\title{
INFLUENCE OF CURING PROCESS INTERRUPT ON ILSS OF THIN CARBON EPOXY LAMINATES
}

\author{
K.Vijaya Kumar ${ }^{1}$, A.S Nagaraja ${ }^{2}$ \\ ${ }^{1}$ Manager, Composite Manufacturing Division, HAL, India \\ ${ }^{2}$ Chief Manager, Composite Manufacturing Division, HAL, Bangalore, India
}

\begin{abstract}
Autoclave curing process of any composite part lasts for about 5 to 6 hrs during which the composite parts will undergo physical \& chemical changes due to the polymerization process. Any interrupts or breakdown during curing process due to mechanical / power / controller failures can affect the properties and in turn results in improper curing of a composite part. Hence there is a prime need to analyze the effects of process interrupt at critical stages of the curing process on part quality and strength. Efforts are made in this paper to study and analyse the effects of curing process interrupts on the properties of Hexcel 913 carbon lepoxy composite laminates of thickness $2 \mathrm{~mm}$ at five critical stages $\left(75^{\circ} \mathrm{C}, 90^{\circ} \mathrm{C}, 110^{\circ} \mathrm{C}, 120^{\circ} \mathrm{C}\right.$, and $\left.135^{\circ} \mathrm{C}\right)$ of a cure cycle. The ILSS (Inter laminar Shear Strength) is analyzed as per Dutch Institute for Norms (DIN) standards and the results are compared with the master specimen. The results exhibits low strength at cure temperatures 90, 110 and $120^{\circ} \mathrm{C}$ for process interrupt of 60 mins due to significant decrease in temperature during the process interrupt and eventually result in incomplete resin transition at critical $T_{g}$ points from 90 to 120 deg.C. The laminates cured with process interrupt for 60 mins at $75^{\circ} \mathrm{C}$ have reduced $0.5 \%$ of the ILSS properties and between 90 to $120{ }^{\circ} \mathrm{C}$ the ILSS has reduced by $4-8 \%$ of the reference laminate properties. Hence the autoclave break down / power failure for more than 40 mins at $90{ }^{\circ} \mathrm{C}$ and 30 mins at $120^{\circ} \mathrm{C}$ is not recommended for curing of composite parts of thickness less than $3 \mathrm{~mm}$ as the part strength gradually decreases. However these conditions vary for curing thicker composite laminates, since it consists of more layers and will have high thermal gradients between the layers during curing. Mathematical equations are formulated to determine the Avg. ILSS values at particular cure temperature for different process interrupt periods. This helps the designer or the manufacturer to evaluate and analyse the ILSS values due to process interrupts at critical points during curing process.
\end{abstract}

Keywords: Autoclave, Curing, Composites, Fiber, Flexural, Laminates, Strength.

\section{INTRODUCTION}

Autoclaves are widely used for processing fiber reinforced composite materials as it is economical to cure complex and larger components. Autoclaves are designed with the latest state - of - art technologies to operate in auto, semi auto and manual mode; hence it has become a versatile tool to produce high quality composite structures. Typically, the curing of composites requires to compact the plies of material, pressing this material against the mold, forcing out volatiles and excess resin, and holding everything motionless during the entire cure cycle, this entails applying controlled levels of heat and pressure.

Sometimes due to unavoidable break down / power failures/ controller failures at any stage during curing process leads to dire consequences and incomplete curing of the composite parts, hence there is a need to understand, analyze and evaluate the properties of the cured parts that are cured in autoclave with the process interrupt in the cure process. The cure temperature and the duration of the process interruption plays a vital role in decision making for a designer to whether accept or reject the cured composite part. Even the part looks cured visually the process interruption at critical stages of the cure cycle affects the molecular network formation and the polymerization reaction. Springer et.al [12] made attempts to model the Heat of Reaction, Degree of
Cure, and Viscosity of Hercules 3501-6 Resin, Mantel et.al [3] explained Cure Kinetics and Rheology Models for ICI Fiberite 977-3 and 977-2 Thermosetting Resins, Shamku et.al [4] explained about the rheological studies with the cure temperature for EPON 862/W Epoxy Used in Pultrusion, similarly Hubert and Kim et.al[5-6] explained the cure kinetics and viscosity model of the Hexcel 8552 and 3501-6 materials, these literatures show behavior of resin viscosity with the cure temperature and time. J.M Khenny and Gordana Bogoeva et.al, [7-8] explained the method for evaluating the cure kinetics for the epoxy resins. Vijaya kumar et.al explained the root causes for the deviations that occurs during curing process of fiber composites in an autoclave. This research attempts to explore the DT and NDT characteristics of these parts that are cured with the process interrupt for $60 \mathrm{~min}$ duration at critical points in the cure process. The Fig. 1 shows a two step cure cycle to cure 913 epoxy composite parts where the first dwell for 40 mins was maintained at $75{ }^{\circ} \mathrm{C}$ and the second dwell for 60 mins was maintained at $135{ }^{\circ} \mathrm{C}$, if the power fails or the autoclave heaters fail at any stage during the curing process the temperature drops maintaining the pressure and vacuum within limits, but the dwell time exceeds beyond the required limit, this situation results in a snag in the curing process, thereby sufficient data or the experimental work is not available to analyze the properties 
and to take decisions. This paper presents an experimental approach where the autoclave heaters are switched off for $20,40 \& 60$ mins during the curing process at five critical temperature points $\left(75^{\circ} \mathrm{C}, 90^{\circ} \mathrm{C}, 110^{\circ} \mathrm{C}, 120^{\circ} \mathrm{C}, 135^{\circ} \mathrm{C}\right.$ ) and the laminates are cured as per the cure cycle. The gel time characteristics of the 913 resin system is as shown in the Fig. 2 which depicts the maximum decrease in viscosity is at $115-120{ }^{\circ} \mathrm{C}$ thereby the resin converts from rubbery to glassy state at this point which is called as the glass transition point for verification, this point is crucial and the resin continues to remain in gel condition for only $15 \mathrm{mins}$. The degree of cure plays an important role on the mechanical properties of the final products which in turn depends on the cure parameters, especially on cure temperature and time. Although companies manufacturing the commercial epoxy prepreg materials usually suggest cure cycles for custom applications, but they are not same for all the parts, since the optimum cure parameters for curing thin and thick composite parts differs. Hence there is a scope to study the influence on mechanical properties due to variation in the cure parameters.

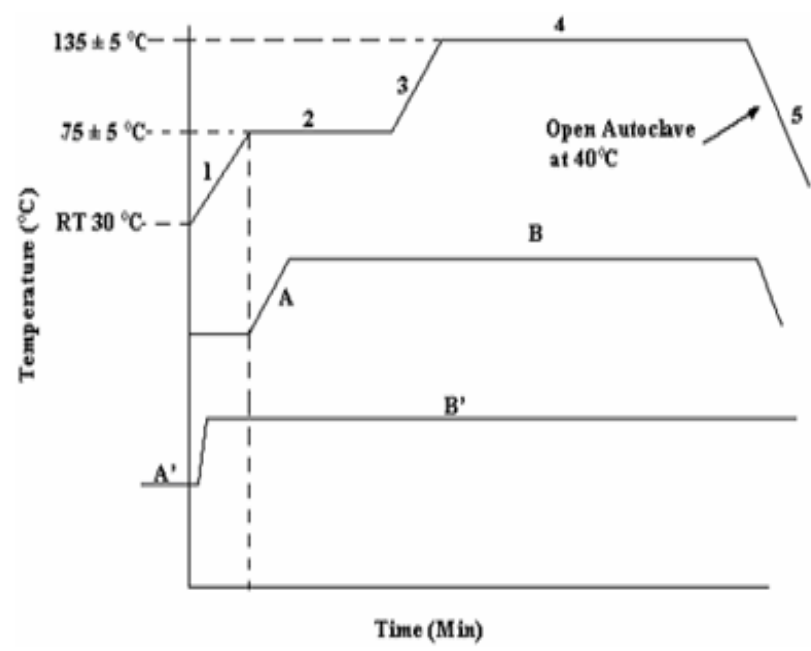

Fig.1 Two stage cure cycle for composite parts

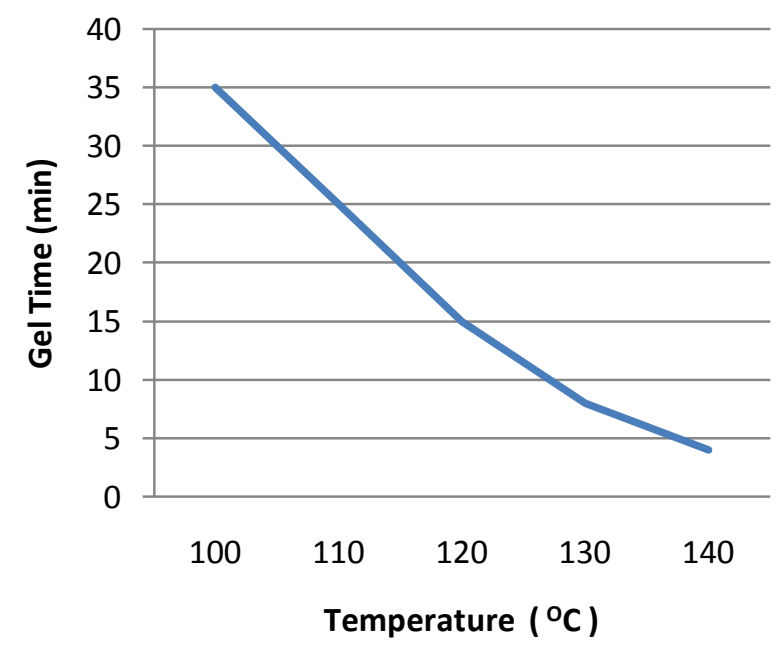

Fig.2 Gel characteristics of 913 epoxy resin.

\section{EXPERIMENTAL WORK}

Six laminates made of carbon epoxy G801 prepreg with 2 $\mathrm{mm}$ thickness and size $200 \mathrm{X} 150 \mathrm{~mm}$ for testing ILSS (Inter laminar shear strength) are fabricated with a symmetric balanced layup consisting 8 layers with an orientation of 0 and 90 degrees [0/90]s. The fabricated laminates are cured in the autoclave as per the schedule as shown in the Table no.1, where the heaters are cut off for 60 mins at five critical points and the process is continued as per the two stage cure cycle mentioned in the Fig.1, The reference Laminate is cured as per the cure cycle without the process interrupt to evaluate and compare the results.

Table 1, Details of the laminates cured with process hold for 60 mins.

\begin{tabular}{|l|l|l|l|}
\hline $\begin{array}{l}\text { Lamina } \\
\text { te No. }\end{array}$ & $\begin{array}{l}\text { Hold } \\
\text { Temperatu } \\
\text { re }\end{array}$ & $\begin{array}{l}\text { Process } \\
\text { Hold } \\
\text { Time }\end{array}$ & $\begin{array}{l}\text { Cure } \\
\text { Temperat } \\
\text { nre }\end{array}$ \\
\hline 01 & 75 & 60 & 135 \\
\hline 02 & 90 & 60 & 135 \\
\hline 03 & 110 & 60 & 135 \\
\hline 04 & 120 & 60 & 135 \\
\hline 05 & 135 & 60 & 135 \\
\hline
\end{tabular}

The cure parameters like external applied pressure inside autoclave and the vacuum applied inside the vacuum bag remains unchanged and maintained as per the recommended cure cycle.

The cured laminates are tested for the presence of internal defects using ultrasonic C-scan and the results are found satisfactory as shown in the Table no. 2 .

Table 2 Details of the C-Scan results of the laminates.

\begin{tabular}{|l|l|l|l|}
\hline $\begin{array}{l}\text { Laminate } \\
\text { No. }\end{array}$ & $\begin{array}{l}\text { Hold } \\
\text { Temperature } \\
{ }^{\mathbf{O}} \mathbf{C}\end{array}$ & $\begin{array}{l}\text { C } \\
\text { Scan } \\
\text { Value, } \\
\text { DB }\end{array}$ & Remarks \\
\hline 01 & 75 & 15 & Satisfactory \\
\hline 02 & 90 & 13 & Satisfactory \\
\hline 03 & 110 & 13.1 & Satisfactory \\
\hline 04 & 120 & 13 & Satisfactory \\
\hline 05 & 135 & 13 & Satisfactory \\
\hline
\end{tabular}

DSC (Differential Scanning Calorimeter) tests were carried out to analyze the relative changes in temperature and energy under isothermal or adiabatic conditions, it is widely used over the years to obtain the information about glass transition temperature ( $\mathrm{Tg})$, melting point $(\mathrm{Tm})$, crystallization temperature (Tc), heat of crystallization $(\mathrm{Hc})$, heat of melting (Hf), and that heat absorbed or evolved during cure reactions or decomposition reactions. During heating, as a solid sample melts and transforms to a liquid state, it absorbs more energy (endothermic) than that of the reference. Similarly, as the crystallization takes place, excess energy is given out (exothermic). As a result, the melting and crystallization processes appear as peaks (endothermic or exothermic) and the area under the curve gives a direct measure of the heat of fusion or crystallization. Kinetics calculations based on a DSC 
heating run that is performed under isothermal or non isothermal conditions provide valuable guidance, not only for the product and process development, but also for optimization of cure cycles for a variety of thermosetting resins.[1], DSC graphs of the five laminates are as shown in the Figs.3-7.

The Degree of cure (DOC) $\alpha$, which is a thermal property obtained with a differential Scanning calorimeter (DSC) has been used extensively to estimate the advancement of curing in the cured laminates.

Degree of cure, $\alpha=\frac{\mathrm{H}}{\mathrm{Hr}}$ where $\mathrm{H}-$ Heat of reaction released up to time t., $\mathrm{Hr}$ - Total Heat of reaction.

The specimens are prepared from the cured laminates with the dimensions of 10 X $20 \mathrm{~mm}$ for Inter Laminar Shear Strength (ILSS) test as per the DIN 29971 standards.

The ILSS (Inter Laminar Shear Strength) signifies the compaction strength or the bonding strength between the fibers and the matrix (resin) in the composite structure.

\section{RESULTS AND DISCUSSIONS}

From the DSC graphs the degree of cure is calculated and the results are tabulated in the Table no.3. as shown below. The degree of cure remains unchanged even the process is Interrupted at different temperatures for $60 \mathrm{mins}$, this is because, as the process is resumed after the heaters are cut off and the temperature is increased to continue the process as to reach the required cure temperature of $135{ }^{\circ} \mathrm{C}$. Since the degree of cure depends on the cure temperature the amount of heat inflow remains same in all the cases. Only the mechanical properties vary due to the process temperature drop and the time during the interrupt of 60 mins, which is due to the rheological behavior of the resin molecules at any instant temperature and time.

Table 3 Details of the degree of cure and the heat flow obtained from the DSC experiments.

\begin{tabular}{|l|l|l|l|}
\hline $\begin{array}{l}\text { Laminate } \\
\text { No. }\end{array}$ & $\begin{array}{l}\text { Curing } \\
\text { Process } \\
\text { Interrupt for } \\
\mathbf{6 0 ~ m i n s ~ a t ~}_{\text {Temp. T }^{\mathbf{0}} \mathbf{C}}\end{array}$ & $\begin{array}{l}\text { Normalized } \\
\text { Heat Flow } \\
\mathbf{J} / \mathbf{g}\end{array}$ & $\begin{array}{l}\text { Degree } \\
\text { Of Cure } \\
\text { (D.O.C) }\end{array}$ \\
\hline 1 & 75 & 6.92 & 95.96 \\
\hline 2 & 90 & 7.14 & 95.92 \\
\hline 3 & 110 & 7.84 & 95.93 \\
\hline 4 & 120 & 7.03 & 96.35 \\
\hline 5 & 135 & 4.69 & 97.56 \\
\hline
\end{tabular}

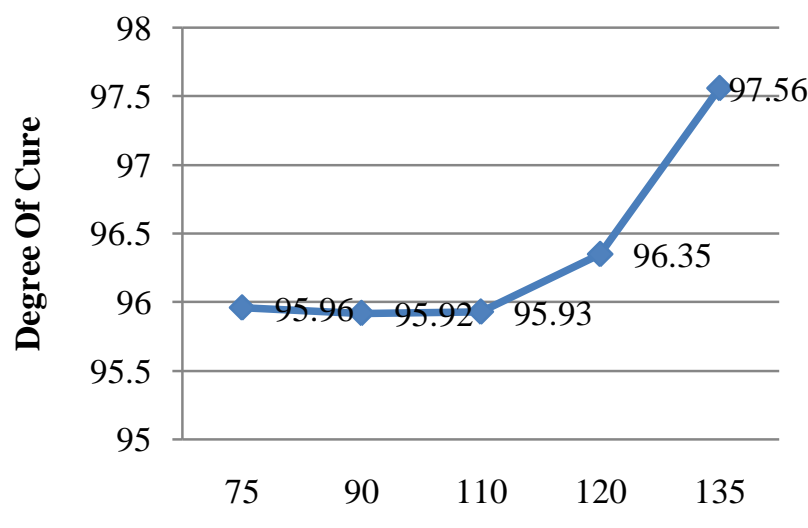

Temperature T. deg.C

Fig.3. Degree of cure curve obtained for the laminates cured.

Ten specimens for each case is prepared and tested as per the standards to obtain the Inter laminar Shear strength (ILSS), which are tabulated as shown in the Table no. 4.

Table 4 Avg. ILSS values.

\begin{tabular}{|c|c|c|c|}
\hline $\begin{array}{l}\text { Laminate } \\
\text { No. }\end{array}$ & $\begin{array}{l}\text { Curing } \\
\text { Process } \\
\text { Interrupt for } \\
60 \text { mins at } \\
\text { Temp. } \\
\mathrm{T}^{\circ} \mathrm{C}\end{array}$ & $\begin{array}{l}\text { AVG } \\
\text { ILSS } \\
(\mathrm{Mpa})\end{array}$ & $\begin{array}{l}\% \\
\text { decrease } \\
\text { in ILSS }\end{array}$ \\
\hline 1 & 75 & 71.63 & 0.51 \\
\hline 2 & 90 & 68.54 & 4.80 \\
\hline 3 & 110 & 67.12 & 6.18 \\
\hline 4 & 120 & 66.27 & 7.95 \\
\hline 5 & 135 & 70.31 & 1.46 \\
\hline
\end{tabular}

All the specimens tested are compared with the standard reference specimen values which have an Avg. ILSS value of $72 \mathrm{Mpa}$ and noticed that the decrease in ILSS due to process interrupt for longer durations at low temperatures is nominal. However it has a high impact at the elevated temperatures. This is due to the process interrupt at elevated temperatures near gel point leads to sudden drop in the process temperature, thereby the mobility of the resin molecules ceases and the cross linking of the resin molecules is incomplete, since the gel time at elevated temperatures is very less, ( for ex. at cure temperature 130 deg.C the gel time is only 6 mins.) Hence power failures or the autoclave breakdown during curing process at elevated temperatures near gel points are crucial and to be carefully monitored. The Avg. ILSS curve is as shown in the Fig. 4. 


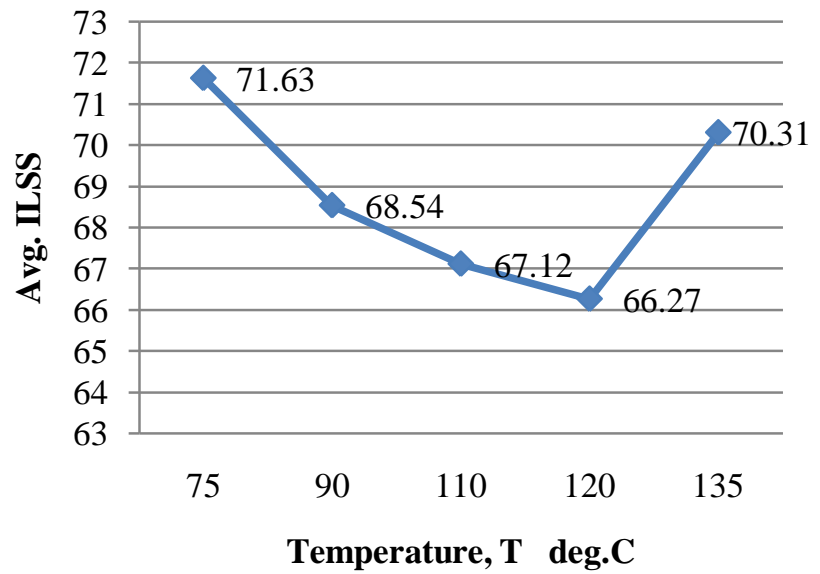

Fig 4 Avg. Inter Laminar Shear Strength (ILSS) curve for the process interrupt at different cure temperatures.

It is observed that the strength of the laminate decreases at cure temperatures 90 deg.C,110 deg.C and 120 deg.C with the process interrupt for 60 mins. Hence the laminates are prepared to test the strength at these temperatures with process interrupt for $20 \mathrm{mins}$ and $40 \mathrm{mins}$ instead of 60 mins. The Interlaminar shear strength results are tabulated as shown in the Table no.5.

Table 5 Avg. InterLaminar Shear Strength ( ILSS) values.

\begin{tabular}{|l|l|l|l|l|}
\hline $\begin{array}{l}\text { Laminate } \\
\text { No. }\end{array}$ & $\begin{array}{l}\text { Curing } \\
\text { Temp. } \\
\mathrm{T}^{\circ} \mathrm{C}\end{array}$ & $\begin{array}{l}\text { Curing } \\
\text { Process } \\
\text { Interrupt } \\
\text { mins }\end{array}$ & $\begin{array}{l}\text { AVG } \\
\text { ILSS } \\
\text { (Mpa) }\end{array}$ & $\begin{array}{l}\% \\
\text { decrease } \\
\text { in ILSS }\end{array}$ \\
\hline 1 & 90 & 20 & 71.41 & 0.82 \\
\hline 2 & 90 & 40 & 70.66 & 1.86 \\
\hline 3 & 110 & 20 & 71.11 & 1.24 \\
\hline 4 & 110 & 40 & 68.05 & 5.49 \\
\hline 5 & 120 & 20 & 70.89 & 1.54 \\
\hline 6 & 120 & 40 & 67.61 & 6.10 \\
\hline
\end{tabular}

From the above table, it is noticed that the process interrupt at 90 deg.C, 110 deg.C and 120 deg.C for 20 mins is acceptable since the avg. percentage decrease in interlaminar shear strength is much lower, where as incase of the process interrupt at these cure temperatures for 40 mins leads to low strength, however at cure temperature 90 deg.C with process hold for $40 \mathrm{mins}$ is acceptable as the avg. strength is still within the acceptable limits. (i.e below $2 \%$ ). However there is no evidence of delamination between the layers or the presence of voids in the cured laminates for all the trials since continuous acceptable vacuum levels are maintained.

It is found from the analysis as shown in the Fig.5 that the decrease in Avg ILSS with the process interrupt time follows the linear curve at cure temperature $90 \mathrm{deg}$.C with equation $\mathrm{y}=-0.26 \mathrm{X}+71.65$ with the correlation $\mathrm{R}^{2}=0.992$, hence this equation helps to find the decrease in ILSS at any process interrupt time $X$. similarly the equations are derived at 110 deg.C and 120 deg.C. However at 120 deg.C the curve is not so linear since the correlation factor $\mathrm{R}^{2}=0.855$.

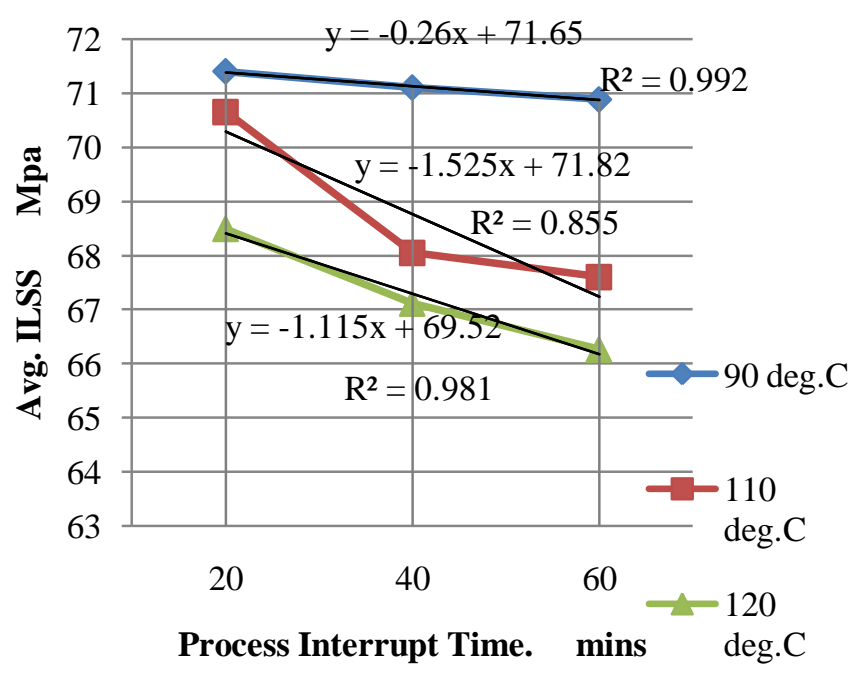

Fig 5 Avg. InterLaminar Shear Strength (ILSS) curve for the process interrupt at different temperatures.

The DSC curves obtained for the cured laminates from the DSC experiments is as shown in the Fig. 6-10

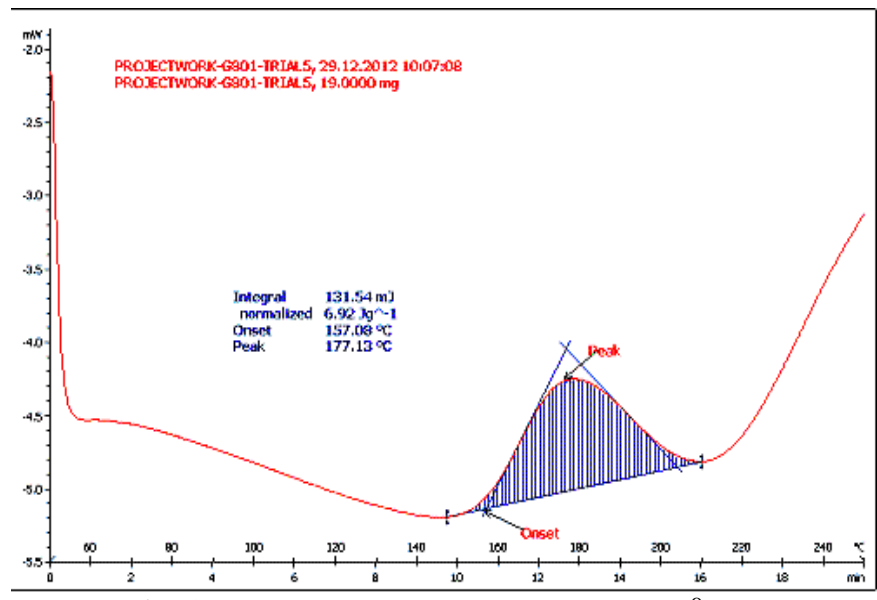

Fig 6 DSC Curve of the laminate $1 .\left(75^{\circ} \mathrm{C}\right)$

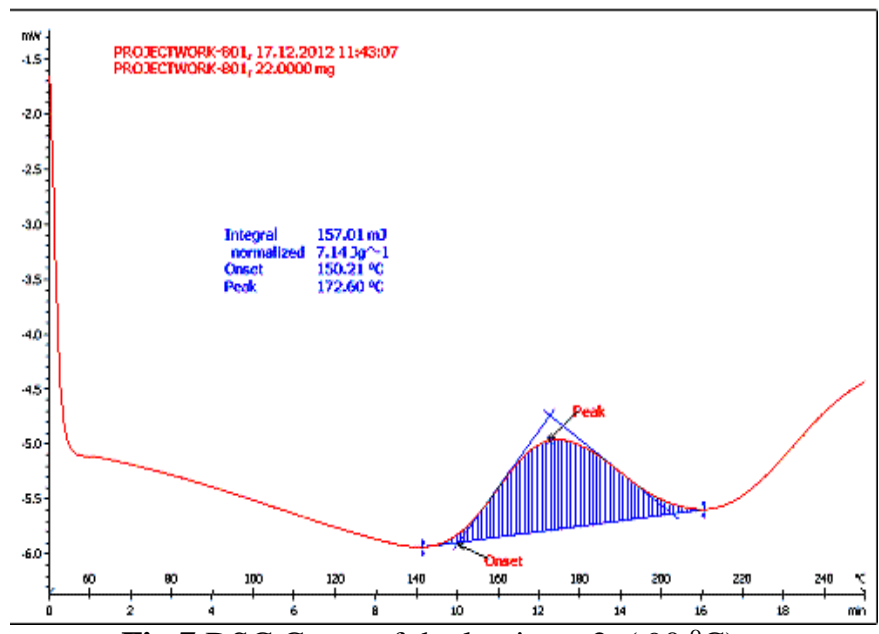

Fig 7 DSC Curve of the laminate 2. $\left(90^{\circ} \mathrm{C}\right)$

It is evident from the DSC (Differential Scanning Calorimeter) curves the normalized enthalpy varies from 5 $\mathrm{J} / \mathrm{g}$ to $7.5 \mathrm{~J} / \mathrm{g}$ as shown in the Figs. 6- 10. This clearly 
depicts that the degree of cure is not changed for the process interrupt at intermediate temperatures. This is because after the process interrupt again the process will be continued and the final cure temperature and the dwell time will be maintained. Hence the degree of cure depends on the process final cure temperature and the dwell time. It clearly indicates that the normalized enthalpy at cure temperature is much lower i.e $4 \mathrm{~J} / \mathrm{g}$ thereby it shows the process interrupt or excess dwell time of 60 mins at final cure temperature 135 deg.C will not have any impact on the strength or the degree of cure. This is due to the laminates are solidified at this temperature.

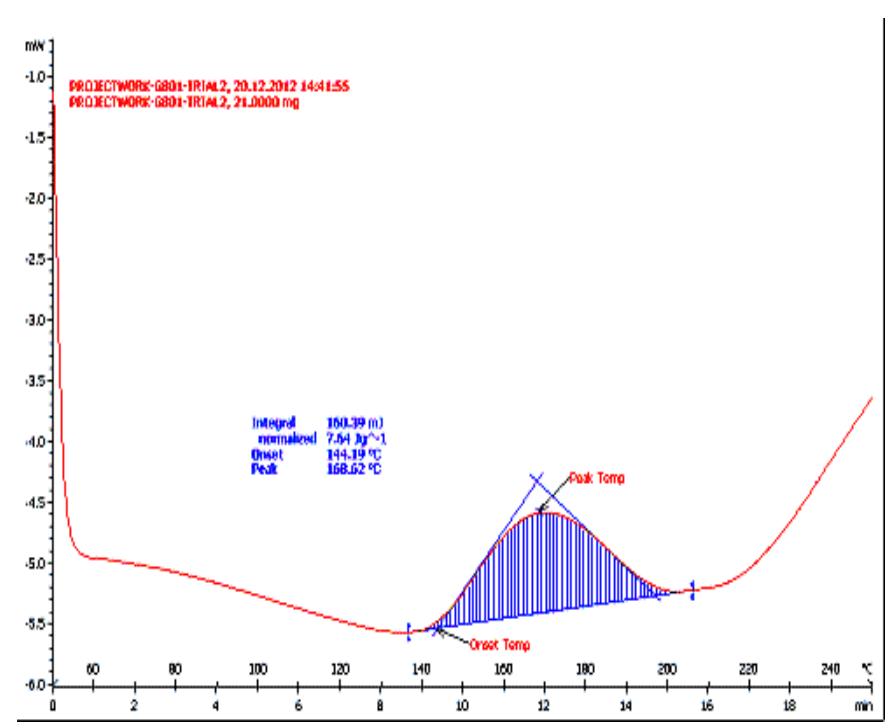

Fig 8 DSC Curve for the laminate $3\left(110^{\circ} \mathrm{C}\right)$

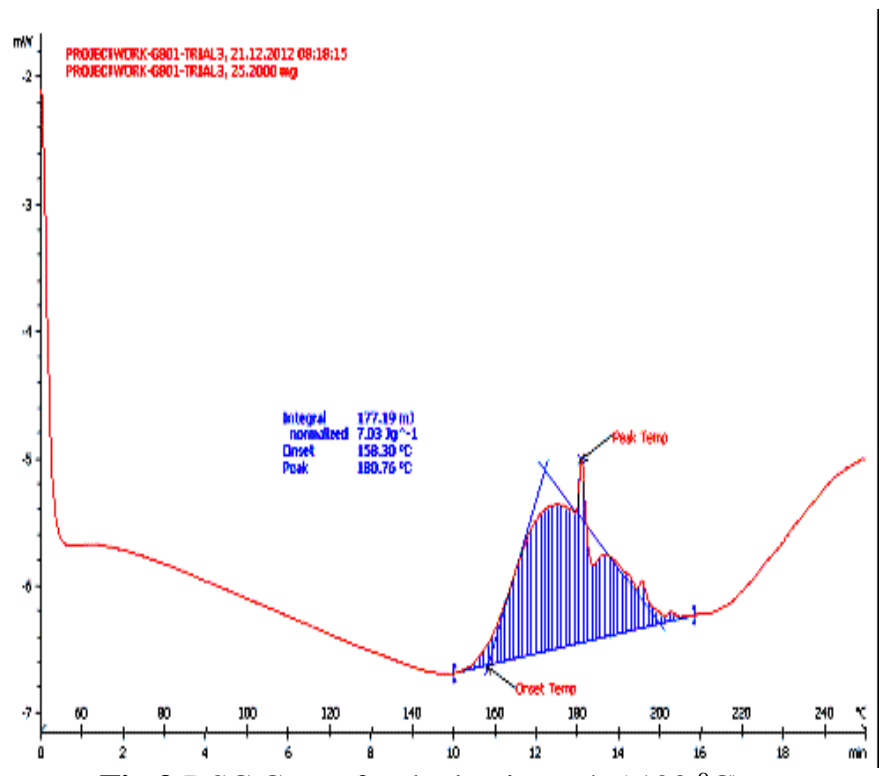

Fig 9 DSC Curve for the laminate $4 .\left(120^{\circ} \mathrm{C}\right)$

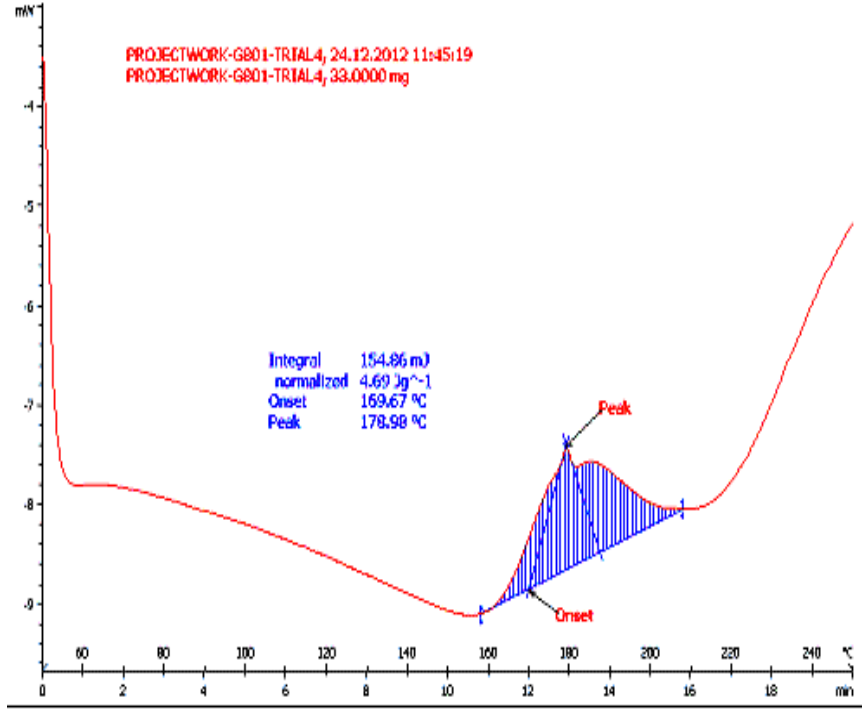

Fig 10 DSC Curve for the laminate $5 .\left(135^{\circ} \mathrm{C}\right)$

\section{CONCLUSION}

The properties of the laminates cured with different interrupt durations during curing process at critical cure temperatures were investigated and also the degree of cure was analyzed by means of DSC curves. The variation in avg. ILSS due to curing process interrupt for different durations at critical temperature points were analyzed. The experimental results show a linear relationship between the avg. ILSS values and the process interrupt duration.. Mathematical equations are formulated to assess the variation in ILSS due to process interrupt at different temperatures. it is noticed that the process interrupt at 90 deg.C, 110 deg.C and 120 deg.C for $60 \mathrm{mins}$ lead to decrease in ILSS from 4 to $7 \%$, however at cure temperature $90 \mathrm{deg} . \mathrm{C}$ with process hold for $40 \mathrm{mins}$ is acceptable as the avg. strength is still within the acceptable limits.( i.e below $2 \%$ ) .

Eventually there was no evidence of delamination between the layers or the presence of voids in the cured laminates for all the trials since continuous acceptable vacuum level was maintained throughout the cure process.

Hence power failures or the autoclave breakdown during curing process at elevated temperatures near gel points are crucial and to be carefully monitored, however the power failures or the process interrupt for smaller duration after cross linking or resin verification doesn't affect much on the ILSS properties and the impact is negligible. Similarly the influence of the curing process interrupts also varies with the thickness and the number of layers in the composite part, since the thicker parts require longer temperature dwell time to achieve thermal uniformity through the part thickness.

\section{ACKNOWLEDGEMENTS}

This work was carried out in Composite Manufacturing Division, Hindustan Aeronautics Limited, Bangalore. I acknowledge sincere thanks to Shri. S.V Suresh. GM, Composite Manufacturing Division, Shri. Krishna Murari DGM ( QA), Shri Mukhopadhayay, DGM(Shop) , Shri 
K.Muralidhar, SM (Shop), Biswal M(QA), Pratheem $\operatorname{Er}(\mathrm{QA})$ for their kind support and encouragement and also to all the members who have helped directly and indirectly to carry out this work.

\section{REFERENCES}

[1]. W. I. Lee, A. C. Loos and G. S. Springer, "Heat of Reaction, Degree of Cure, and Viscosity of Hercules 3501-6 Resin," Journal of Composite Materials, Vol. 16, pp. 510$520,1982$.

[2]. M. R. Dusi, W. I. Lee, P. R. Ciriscioli and G. S. Springer, "Cure Kinetics and Viscosity of Fiberite 976 Resin," Journal of Composite Materials, Vol. 21, pp. 243261,1987.

[3]. S. C. Mantell, P. R. Ciriscioli and G. Almen, "Cure Kinetics and Rheology Models for ICI Fiberite 977-3 and 977-2 Thermosetting Resins," Journal of Reinforced Plastics and Composites, Vol. 14, pp. 847-865, 1995.

[4]. R. Shanku, J. G. Vaughan and J. A. Roux, "Rheological Characteristics and Cure Kinetics of EPON 862/W Epoxy Used in Pultrusion," Advances in Polymer Technology, Vol. 16, pp. 297-311, 1997.

[5]. P. Hubert, A. Johnson, A. Poursartip and K. Nelson, "Cure Kinetics and Viscosity Models for Hexcel 8552 Epoxy Resin," 46th International SAMPE Symposium, pp. 2341-2354, 2001

[6]. J. Kim, T. J. Moon and J. R. Howell, "Cure Kinetics Model, Heat of Reaction, and Glass Transition Temperature of AS4/3501-6 Graphite-Epoxy Prepregs," Journal of Composite Materials, Vol. 36, pp. 2479-2498, 2001.

[7]. M. Ivankovic, L. Incarnato, J. M. Kenny and L. Nicolais, "Curing Kinetics and Chemorheology of Epoxy/Anhydride System," Journal of Applied Polymer Science, Vol 90, pp. 3012-3019, 2003.

[8]. Gordana Bogoeva et.al, " A Rapid Method for the evaluation of Cure Kinetics of Thermosetting Polymers", Macedonian Journal of Chemistry and Chemical Engineering.Vol.32,No.2, pp.337-344(2013).

[9]. K.Vijaya Kumar et.al, "Root Cause Analysis of Heating rate deviations in autoclave curing of CFRP structures" IJIRS ( International Journal Of Innovative Research \& Studies) ISSN 2319-9725 Vol 2, Issue 5. May 2013

[10]. K.Vijaya Kumar, Krishna Murari et.al, Analysis of deviations in Autoclave curing of fiber Composite parts using RCCA ( Root Cause Corrective Action) methodology , Journal of Mechanical and Civil Engineering ( IOSRJMCE) e-ISSN:2278-1684, p-ISSN:2320-334X, Vol. 11,Issue 1,Ver.IV - Feb 2014.

\section{BIOGRAPHIES}

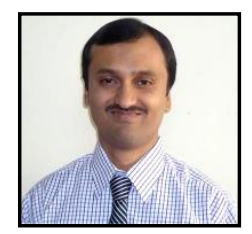

K. Vijaya Kumar, manager at Hindustan Aeronautics Limited, Bangalore. Currently he is pursuing his Ph.D under VTU Belgaum at Ghousia College of Engineering Ramanagaram; His current research areas include 1. Processing of advanced fiber composites 2. Natural fiber composites 3.Nano composites 4.Structural Health Monitoring of composites \& 5.Self Healing Composites.

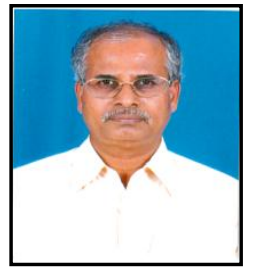

Applications.
A.S Nagaraja, Chief Manager at Hindustan Aeronautics Limited, Bangalore. He has over 25 years of experience in fiber composite materials and his field of interest is on design and development of Advanced light weight composite parts for Aviation 